\title{
New money: are we ready to take on the impacts of a cashless society? A fantasy pitch
}

\author{
Matthew Khong ${ }^{\mathrm{a} 1}$ and Marisol Escobar ${ }^{\mathrm{a}}$ \\ ${ }^{a}$ University of Queensland, Australia
}

\begin{abstract}
This paper is a written account of the pitching research experience two UQ Research Scholars' (Matthew \& Marisol) underwent, as part of the UQ Summer Research Program. It elaborates the use of Faff's (2015) pitching research framework by the duo to develop a full 'fantasy pitch' in studying how the usage of digital money can alter the social construct, and the value of money. Comments on how the individuals has benefited from such a learning experience can be found at the end of the paper in 'personal reflections'.
\end{abstract}

Keywords: blockchain technology, digital currency, social construction of money, pitching research, fantasy pitching

JEL codes: E03, D03, G02

\footnotetext{
${ }^{1}$ Corresponding author: Matthew Khong, UQ Business School, The University of Queensland, Queensland 4072 Australia. Email addresses: m.khong@business.uq.edu.au; m.escobarsolis@uq.net.au
} 


\section{Introduction}

The UQ Summer Research Program is one of the many initiatives set up by the UQ advantage office (UQAO) to provide non-research students with an opportunity to gain research experience working alongside an academic or research professional over the summer break. By participating, students are able to extend their knowledge in their area of interest and develop analytical, critical thinking and communication skills. As part of the UQ Summer research program 2016-7, six UQ Summer scholars were chosen to participate in a 10 -week program to build on the success of the "pitching research" template developed by Faff (2015).

The named authors are two of these scholars and we teamed up on several exercises in the summer program. In one such paired activity, we completed a fantasy pitching task. Fantasy pitching requires us to design our own hypothetical pitch from scratch, following an imaginary yet realistic approach. The current pitching research letter aims to serve as an account of our group's fantasy pitch experience. Our group's final pitch was developed in line with Faff's (2017) pitching research template which was subsequently used as a guide to facilitate a 10-minute PowerPoint pitch as an end deliverable.

Our team consists of two postgraduates of somewhat diverse background. Matthew (author \#1) is an overseas student from Singapore, who intends pursuing an Honours degree in the near future, while Marisol (author \#2) is an exchange student from Peru in her final semester. In his bachelor of business management, Matthew majored in international business, while Marisol did a bachelor of industrial engineering. Interestingly, during the course of developing our team's pitch, synergy was achieved and our team was able to produce a pitch that met the objectives of the fantasy pitching exercise.

The remainder of this pitching research letter is organised as follows. Section 2 provides a brief commentary on the completed fantasy pitch, while Section 3 covers personal reflections from both members of the team. Lastly, this paper concludes in Section 4.

\section{Brief Commentary on Fantasy Pitch}

The completed Fantasy Pitch is shown in Table 1. The topic our team chose is about a new form of digital currency made possible with the advances of technology. With blockchain technology seemingly enlarging its footprint in recent years, our team aspired to explore the consequences of such a development and its impact on the social construction of money. This gave rise to our primary research question (Item B): What is the relationship between using digital money and the social construction 
of money? In doing so, the study aims to explore the societal effects of using digital currency. With regard to the key research papers (Item C), the team was exposed to several recent newspaper articles around the topic of 'dirty money' with the aim to eventually select an article within an area of research we found was worth looking into. The article that we chose was titled "Central banks look into the future of money with blockchain technology trial" (Eyers, 2016) which became our first key paper. Additionally, we found a doctoral dissertation (Shaw, 2016) which addressed, at a very general level, the social valuation processes of money at the advent of digital currency. This paper was critical as it forced us to take one step further by specifically analysing the relationship between both variables. It is also notable that for the purpose of the exercise, our team 'created' a fake paper to simulate an actual pitch. We were allowed to do this, provided that we can justify the intent of doing so. This paper would later hold and possess the measurement scales required to perform our social experiment for items E (Idea), F (Data) and G (Tools). As such, items A, B and $\mathrm{C}$ led us to our motivation (Item $\mathrm{D}$ ), which was to examine the relationship between using digital money and how it affects the societal conception of money.

In idea (Item E), our team pitched to demonstrate how the social construction of money can be shaped as we move into the realm of paperless money, or digital currency. The central hypothesis was that newly introduced digital money would have a significant impact on the social construction of money, and as a result create a variance in value (See Figure 1). In order to achieve our team's proposition, we suggested a social experiment within ethical considerations to be conducted in order to explore and answer our research question. The results will justify why such a study should be conducted (Item H\&I), and also explain the benefits such a study will bring if the study is completed $(\mathrm{J})$. Details of which can found from the pitch in items $\mathrm{H}$ to K in Table 1.

\section{Figure 1. Mickey Mouse Diagram Characterising Novelty of Research Data}

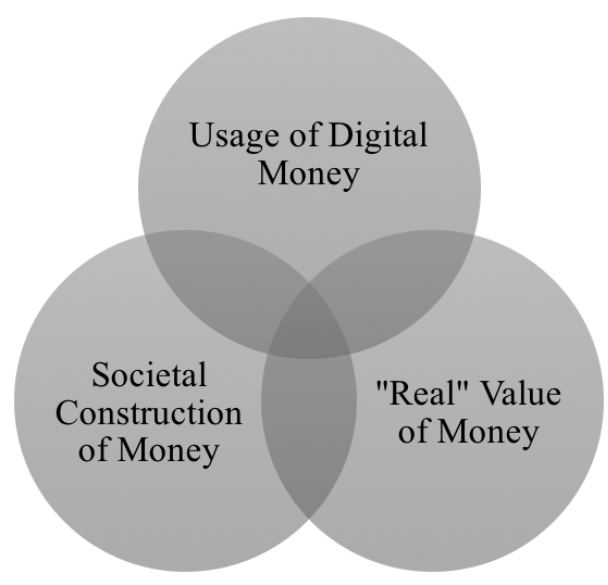

Vol. 16, No. 4 
Table 1. Complete Pitch of "New Money: Are we ready to take on the impacts of a cashless society?"

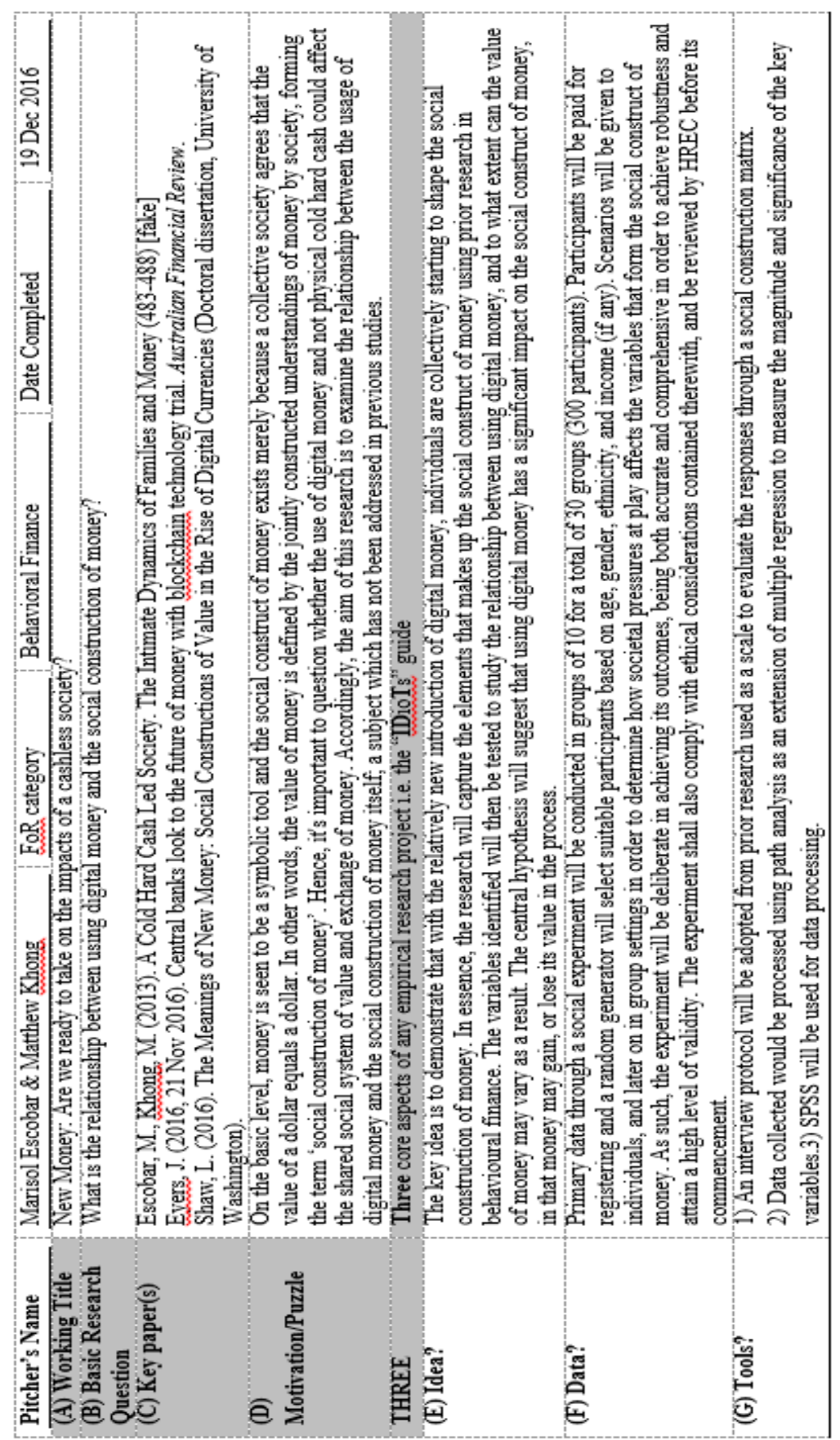




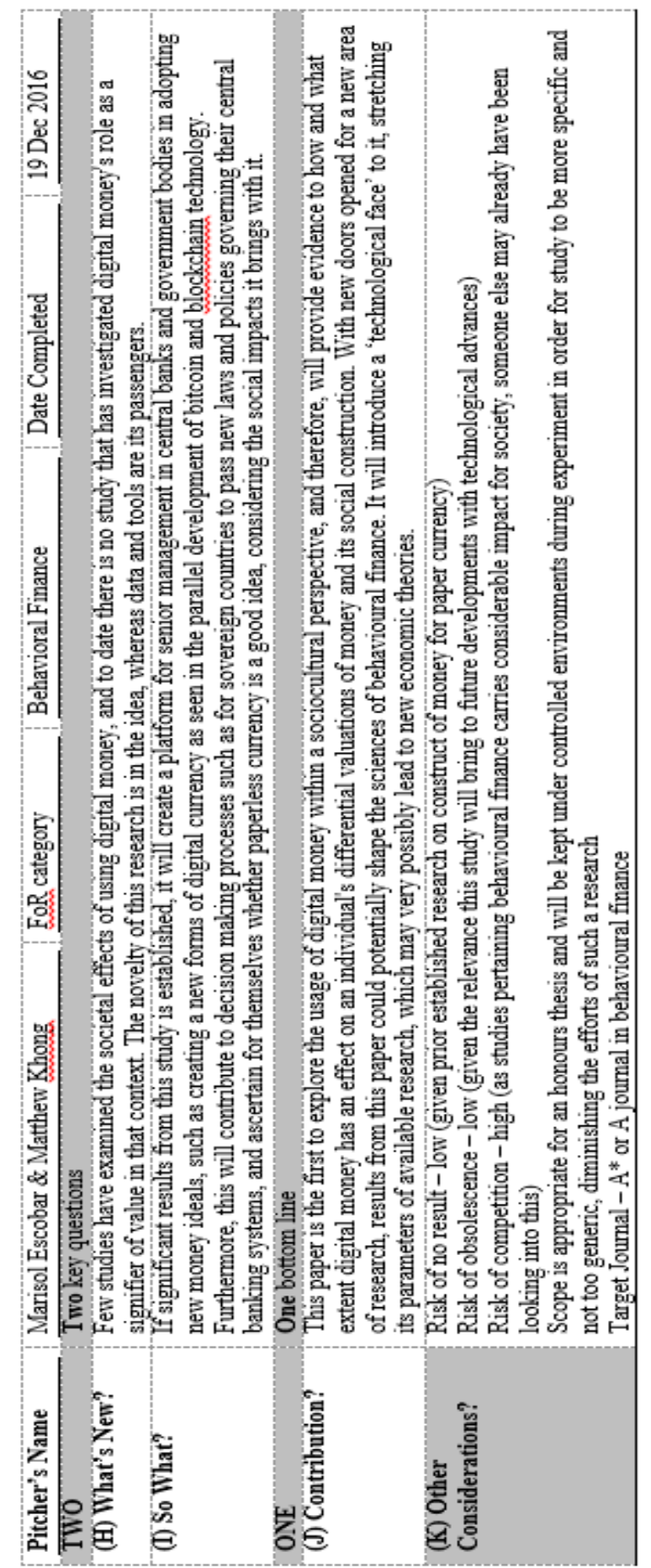

Vol. 16, No. 4 


\section{Personal Reflections}

\subsection{Matthew Khong}

The fantasy pitching activity was probably one of the more challenging and exciting activities thus far into the UQ Summer research program. From the activity, our teams were given the opportunity to take 'ownership' of an actual pitch (although simulated). The exercise facilitated my learning processes greatly and helped me attain a deepened understanding through hands on experience, which otherwise could not be achieved with the previous activities. E.g. reverse engineering and sparring activity (see Faff $e t$ al., 2017b).

By having to research and develop an area of interest from the set topic, our team was forced to think 'out of the box' to derive a meaningful and at the same time, useful research pitch. To me, this was the most challenging part of the exercise, and I am now fully convinced that starting is indeed the hardest part of doing research. Additionally, I also learnt the importance of providing specific information in this exercise. After some discussion with Prof Robert and later with my teammate Marisol, our team realised that a good pitch is one that pays attention to detail, while remaining succinct. It is one that is specific to the extent that it accommodates the feasibility of the research. In other words, the pitch should be as realistic as possible so the chances of success can be increased. I am convinced the invaluable lesson learnt from this exercise will help my development as I embark on my Honours year.

\subsection{Marisol Escobar}

When I read Faff et al.'s (2017a) Fantasy Pitch paper at the beginning of the Summer Program, I was immediately intrigued by the novelty of the exercise. Thus, when the teams were formed and the instructions of the task were announced I already had high expectations for the development of this activity.

Despite having been given the topic of 'dirty money' and chosen a key paper (which was a news article), it was challenging for us to come up with innovative research ideas. In addition, we were advised to link the chosen topic to a past paper that we had reverse-engineered in a previous exercise, which made the task even more ambitious. Nonetheless, after passing this 'critical first stage' we started thinking more fluently and further developing our study. The pitching template helped us to organize our creative thoughts and therefore, structure our research right from the very start.

Another aspect worth mentioning is the learning that came from the feedback received after our presentation. Listening to the comments and criticisms from a high-achieving research professor helped us assess our strengths and weakness as novice researchers. For instance, Matthew and I recognize that to produce good research, concrete statements and strong supporting ideas are needed for making the research as realistic as possible. 
Overall, my expectations from this exercise were met. Fantasy pitching allowed me to explore the research methodology and usefulness of the pitching template from a fun and interesting perspective. In addition, I was able for the first time to develop my 'own' research and have a choice in every dimension of it which certainly made the experience more valuable.

\section{Conclusion}

This letter outlines the Fantasy Pitch developed on the topic of digital money and its social construction. In all, Faff's (2015) pitching research template was successfully used to set the stage in serving as a 'learning tool' for our team. By adhering to the framework, it carefully shaped our individual critical thinking processes, leading our team towards a successful pitch presentation. Both members of the team felt that the fantasy pitch exercise has greatly helped them attain a deepened level of understanding towards research, which will definitely prove useful in their future endeavors.

\section{References}

Eyers, J. (2016) "Central banks look to the future of money with blockchain technology trial", Australian Financial Review, 21 Nov. 2016, available online at http://www.afr.com/technology/central-banks-look-to-the-future-of-moneywith-blockchain-technology-trial-20161117-gss4nd

Faff, R. (2015) “A Simple Template for Pitching Research”, Accounting and Finance, 55: 311-336

Faff, R. (2017) "Pitching Research", Available at SSRN: http://ssrn.com/abstract=2462059

Faff, R., Ali, S., Atif, M., Brenner, M., Chowdhury, H., Crudas, L., Joubet, A., Malik, I., Mi, L., Nagar, V., Pullen, T., Siegrist, M., Smythe, S., Stephenson, J., Zhang, B., and Zhang, K. (2017a) "Fantasy Pitching", Accounting and Management Information Systems, Vol. 16, No. 2: 360-379

Faff, R.W., Carrick, R., Chen, A., Escobar, M., Khong, B.X.M., Nguyen, B.H. \& Tunny, W. (2017b) "Pitching Research: A Reverse-Engineer "Sparring" Experiment with UQ Summer Research Scholars" (January 23, 2017), Available at SSRN: https://ssrn.com/abstract $=2903811$

Shaw, L. (2016) The Meanings of New Money: Social Constructions of Value in the Rise of Digital Currencies, Doctoral dissertation, University of Washington 